\title{
Radicalizing Arab University Students: A Global Emerging Threat
}

\author{
Diab M. Al-Badayneh \\ Police College, MOI, Qatar \\ IKCRS, Amman, Jordan \\ Maher Khelifa \\ Qatar University, Qatar \\ Khawla Alhasan \\ Qatar University, Qatar \\ IKCRS, Amman, Jordan
}

\begin{abstract}
The purpose of the study was to explore the factors mediating college students' radicalization. A sample of 1,116 students was drawn from four different Jordanian universities. The construct validity of the scale was estimated by calculating the correlation between the radicalization items and the negative emotion items. A positive significant relationship was found $(0.12, \alpha=0.000)$, a sign of validity of the scale. The scale reliability was also strong and was estimated at 0.90 using Cronbach Alpha. Factor analysis produced five factors explaining $45 \%$ of the total variance of radicalization. The first factor labeled "political radicalization" explained $18.5 \%$ of the variance, the second factor "religious radicalization" explained $12.7 \%$, the third factor "violent radicalization" explained $6.4 \%$ of the variance, the fourth "group radicalization" accounted for $4 \%$, and the fifth factor "social radicalization" only accounted for $3 \%$ of the total variance. Significant differences in student radicalization were found according to the geographical region of the university (North, Center and South), $F=14, \alpha=0.000$. However, no significant differences were found in radicalization as it relates to gender, and type of college (i.e., Humanities vs. Pure Sciences).
\end{abstract}

Keywords: radicalization, religious, social, political, group, college students, Jordan

\section{Introduction}

Anecdotal evidence suggests that the university environment is a fertile ground for radicalization and the recruitment of radicals. In the Arab world, the university student population is typically large and made of young, marginalized, disenfranchised, fragile and easily influenced individuals. University students don't typically come under close scrutiny, from a security standpoint, unless they are very visible and prominent opposition political activists (Al-badayneh, 2012). Given their age and developing intellectual maturity, university students constitute an easy target and are often easily influenced and persuaded to affiliate with terrorists and to later participate in or carry out on their own terrorist activities. The university setting thus

Diab M. Al-Badayneh, Professor of Applied Sociology, Police College, MOI; IKCRS.

Maher Khelifa, Associate Professor, Department of Social Sciences, Qatar University.

Khawla Alhasan, Assistant Professor, Department of Social Sciences, Qatar University; IKCRS. 
provides an ideal, safe and accessible environment and terrorists may see the university environment as the perfect ground to recruit naïve, gullible, unhappy, angry and disgruntled youth who may anticipate unemployment and who may have already developed a sense of social injustice and inequality. Young student recruits usually disseminate radical thoughts and plans among their peers and to the wider society, and as such become recruiters themselves.

Radicalization means different meanings to different researchers. Radicalization is a relatively new concept and a buzz-word in counterterrorism, policy-making and academic research (Richard, 2011). Understanding radicalization and the formation of radical group in the Arab world drives beyond the traditional criminological, sociological and psychological explanations offered by Western scholars and experts of violence. Radical groups, like terrorists groups in the Arab world, are distinct in their formation, structure and function. Radical group formation is affected by traditional social bonds, general strains, and social investment (Al-badayneh, 2012). Research into radicalization does not pay much attention to education in general (Pels \& de Ruyter, 2012) and especially to the university setting as a breeding ground for terrorism. This is clearly a forgotten yet important likely influence in the process of radicalization.

Theorists, researchers, and practitioners, in the area of terrorism believe that terrorism depends on the radicalization of its initiators and perpetrators (Horgan, 2005a). Sageman (2007) stated that "the understanding of this process of 'radicalization' is critical to assessing the threat facing the West and should be the basis guiding our interventions to counter it" (p. 1). Therefore, understanding and combating radicalization would appear to be an important prerequisite for effectively combating terrorism (Mandel, 2010). Empirical research has indicated that the level of education of radicalized people does not have a strong influence on the prevention or recruitment of radicals (Silke, 2008). Among radicalized people, one can find all educational levels (Webber, 2011). However, theoretically, one can say that parents, teachers, and faculty members who are radicals can transmit their radical beliefs and thoughts to young students. In contrast, it is reasonable to assume that students will adopt democratic ideas if these are fostered by educators (Pels \& de Ruyter, 2012). Empirical research reveals similarities between the definitions of concept of radicalization and terrorism in i.e., threat violence, force, political and fear (Weinberg, Pedahzur, \& Hirsch-Hoefler, 2004).

Al-badayneh (2010) noted that the relationship between radicalization and terrorism is not causal; radicalization may operate as a path to terrorism. Radicalization can occur with any extremist group in any society. Groups that support nationalistic movements, environmental issues, religious extremism, political ideology, animal rights, and political independence are examples of radicalization. Radical groups are, however, not equally dangerous (Pressman, 2008). Radicalization is by definition a process of change in which non-violent individuals come to endorse and promote violent activity. Brian Michael Jenkins, as cited in Gartenstein-Ross, Goodman, and Grossman (2008), states that "terrorists do not fall from the sky...they emerge from a set of strongly held beliefs. They are radicalized. Then they become terrorists". Other meanings of radicalization come from social psychological distinctions among belief, feeling, and behavior. In a political context this means increasing time, money, risk-taking, and violence in support of a political cause. One can argue equally say that behavioral radicalization means increasing time, money, risk-taking, and violence in support of a political group (McCauley \& Moskalenko, 2008).

Radicalization in the Arab World does not differ in its essence from radicalization in other parts of the world. It is often shaped by religion extremist thoughts mixed with some social and cultural taboos. Not all radicals adopt the use of violence to achieve political and social goals. Most of them believe and support other violent 
radical groups but not get involved in violence, and some times, they become de-radicalized and adopt more acceptable social behavior (Al-badayneh, 2012).

In Europe, radicalization refers to "the process of adopting an extremist belief system and the willingness to use, support, or facilitate violence and fear as a method of effecting changes in society" (Precht, 2007). In Canada, the term radicalization is defined by Royal Canadian Mounted Police (RCMP) as "the process by which individuals are introduced to an overly ideological message and belief system and taught or encouraged to follow thought and behavior patterns that could eventually (but not always) lead to extremist activity or direct action (RCMP, 2007). As can be seen from this definition, radicalization does not often assume the adoption of violence. The Dutch intelligence agency, AIVD, defines it as a readiness to pursue or support far-reaching changes in society that conflict with, or pose a threat to, the democratic order (HIS, 2006, cited in Parent \& Ellis, 2011, p. 10).

\section{Method}

The term radicalization in this study refers to individuals using religion, politics, social or any other means to justify the use of threats or violence. Currently, there are few research studies and research instruments investigating the subject of radicalization. This may be attributed to the fact that radicalization was associated with terrorism prominently following the terrorist attacks of 9-11.

\section{Design}

This research followed a descriptive survey design. The study was quantitative in nature and included a number of instruments including questionnaires and scales designed to explore various dimensions of radicalization. The battery of instruments used was derived from available literature and were initially produced in the Arabic language as they were meant for an Arab native audience.

\section{Participants}

A total of 1,116 students were drawn from 10 mandatory classes in four public universities in Jordan. Students taking these courses were 20 years of age on average and belonged to different educational levels and different university colleges. The demographics of the sample included $40 \%$ males and $60 \%$ females, $60 \%$ from the Humanities and $40 \%$ from the Sciences, $40.7 \%$ were first level students, $70 \%$ identified themselves as Eastern Jordanians, and more than a third of the sample (37.2\%) indicated that their father were unemployed.

\section{Instruments of Data Collection}

Therefore, items for the radicalization scale that were developed for the present study were derived from available literature on radicalization, terrorism, and other relevant theories. The questionnaire was written in Arabic and covered all theoretical aspects of radicalization including micro and macro levels. The questionnaire consisted of the following parts:

- Demographic variables consisting of personal information (i.e., age, job, education, etc.).

- Life Satisfaction Scale; a one-item nominal scale.

- Stressful Life Events Scale consisting of 10 items such as divorce or death of loved ones.

- Negative Emotions Scale consisting of four major emotions including anger, fear, depression and anxiety. Students were asked to indicate their feeling on theses emotions on a scale comprising three responses, i.e., not at all, sometimes, and most of the time.

- Radicalization Scale (RS) consisting of the 51 items distributed across the following factors: 
(1) Political radicalization;

(2) Religious radicalization;

(3) Violent radicalization;

(4) Religious centralism;

(5) Social radicalization.

\section{Procedure}

Participants were recruited voluntarily from 10 mandatory classes in four public universities in Jordan. All participants were requested to read and sign a brief consent form and ask any questions that they may have about the study, their involvement or about the administered instruments of data collection. Participants were asked to fill out all the instruments and to put them in a brown envelop the researchers made available for them after they finish filling out the instruments.

\section{Results}

The construct validity of the scale was estimated by calculating the correlation between the Radicalization Scale and the Negative Emotion Scale. Results showed a positive significant relationship of $0.12, \alpha=0.001$, indicating that the scale is valid. Further, the Cronbach Alpha for the 51-item Radicalization Scale was high (0.90) suggesting a high internal consistency of the scale. In testing the correlation matrix and sampling adequacy, Correlation coefficients were computed and were found to be statistically significant. The determinant was not equal to zero $(\mathrm{D}=0.55)$, and the correlation matrix is not singular, and statistically significant using the Bartlett's test of sphericity $(\chi=20947.6, \alpha=0.000)$ meaning that the correlation matrix is not an identity matrix.

Kaiser-Meyer-Olkin (KMO) test was used to examine sample adequacy (homogeneity of the sample), and the KMO value in this study was 0.913 , a value greater than Zero. Kaiser (1974) recommended that values greater than (0.5) are acceptable, values between (0.7-0.8) are good, and values between (0.8-0.9) are great, and values above (0.90) are superb.

Factor analysis components (FAC) with Direct Oblimin with Kaiser Normalization rotation through SPSS (version 22) was used initially to estimate empirically the number of factors and to determine which questions are to be retained. Applying Kattell (1966), a scree plot was examined and eigenvalue analysis (i.e., eigenvalue $\geq 1$ ) suggested a 5-factor solution was appropriate for the data (see Figure 1). The factor analysis used Direct Oblimin with Maximum likelihood rotation with Kaiser-Meyer-Olkin Measure of Sampling Adequacy stopping rule. A factor solution was identified as a resolution of factor analysis and the scree plot analysis revealed that the 5 factors accounted for (49\%) of the variance on the scale.

Table 1 shows that factor analysis produced five factors explaining $45 \%$ of the total variance. The first factor corresponded to "political radicalization" explained $18.5 \%$ of the variance. The second factor "religious radicalization" explained $12.7 \%$ of the total variance and the third factor "violent radicalization" explained $6.4 \%$ of the variance. The fourth factor was "religious centralism" accounting for $4 \%$ of the variance and the fifth factor was "social radicalization" and accounted for $3 \%$ of the total variance. 


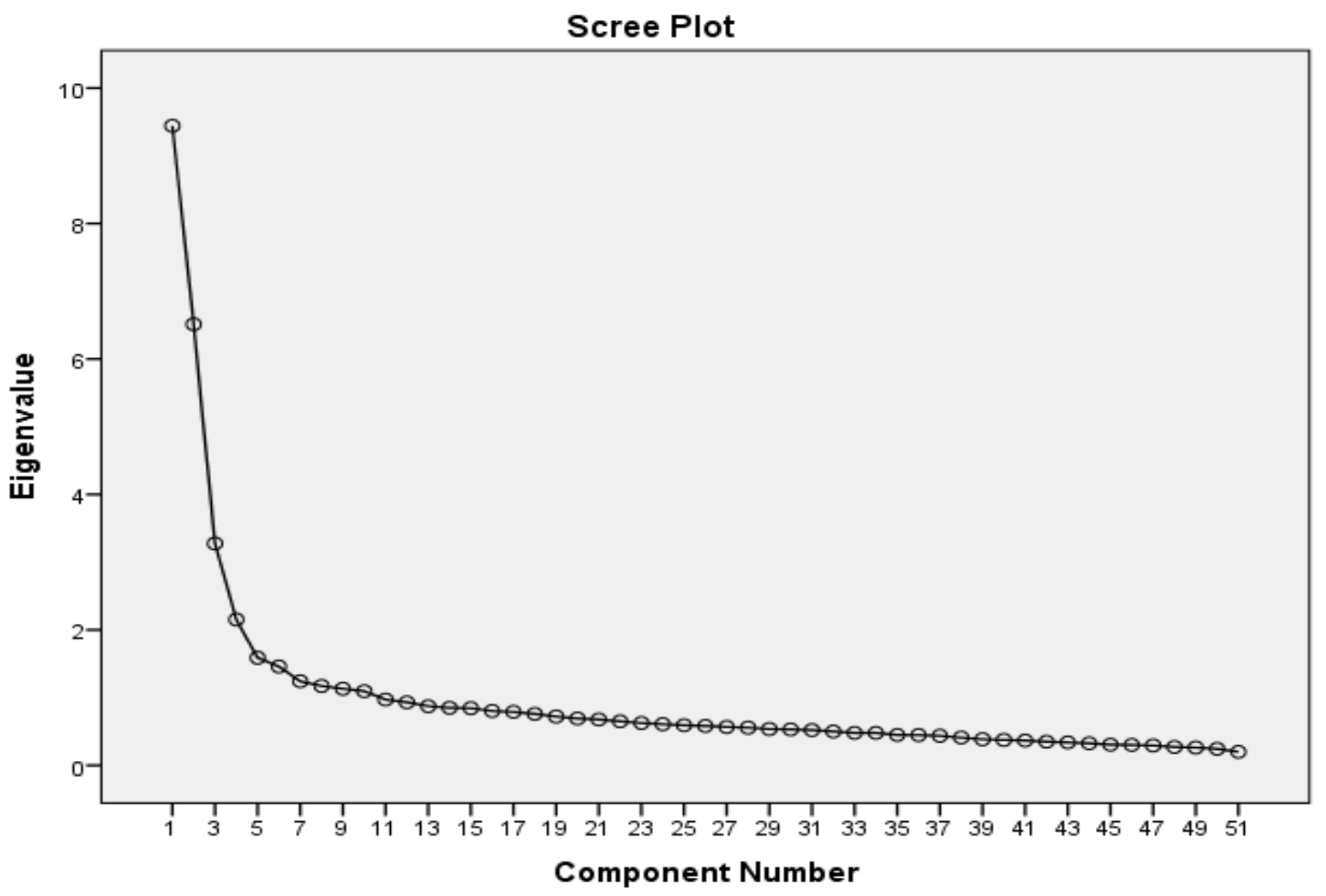

Figure 1. Scree plot representing the number of radicalization factors.

Table 1

Rotated Component Matrix ${ }^{1}$

\begin{tabular}{ll}
\hline Factor/Items & loading \\
\hline Factor 1: Political radicalization & $\mathbf{9 . 4}$ \\
\hline Using pressure on political regime is the only means for reform & 0.656 \\
Using peaceful means in resolving conflicts is a sign of weakness & 0.652 \\
Change and political reform come through force & 0.646 \\
Exercise of force is the only way to subdue political opponents. & 0.602 \\
Democratic system with multi-party system create chaos & 0.599 \\
Discussion of political ideas with opposition is a waste of time & 0.545 \\
Applying my political views by force & 0.516 \\
My enemy is anyone who opposes my political views & 0.515 \\
\hline Factor 2: Religious radicalization & $\mathbf{6 . 5}$ \\
\hline Martyrdom for God's sake will protect the Nation & 0.805 \\
Nations progress only when people adhere to religion & 0.789 \\
Religious government agencies must monitor the application of religious orders & 0.733 \\
Religious authorities are the only source of power and authority in society & 0.732 \\
The unity of the Nation can only be accomplished through religious action only & 0.711 \\
War is the only way to preserve religion & 0.573 \\
Progress of our civilization is achieved when we adhere to religious norms & 0.536 \\
Converts to other religions deserve to die & 0.494 \\
War is the best volunteer endeavor for the prosperity of the nation & 0.459 \\
\hline
\end{tabular}


(Table 1 continued)

\begin{tabular}{|c|c|}
\hline Factor/Items & loading \\
\hline Factor 3: Violent radicalization & 3.3 \\
\hline Attacks on my civilian enemy's (as in September 11th 2001) are justified & -0.875 \\
\hline Using violence to create a safer world is acceptable (as in September 11th 2001) & -0.692 \\
\hline Nothing is wrong with using violence to serve the nation & -0.529 \\
\hline Nations advance only through the use of force & -0.496 \\
\hline Force alone can defeat our enemies & -0.466 \\
\hline A woman with sexual relationship deserves murder by her family & -0.433 \\
\hline The unification of the nation can only be done by force & -0.398 \\
\hline Factor 4: Group radicalization & 2.2 \\
\hline The rape of a girl of my religious group is like a rape of my daughter & 0.734 \\
\hline The killing of a young man of my religious group is like a killing of my brother & 0.699 \\
\hline My religious group is the only source of authority & 0.595 \\
\hline Insult of a person of my religious group is like a personal insult & 0.577 \\
\hline The trial of a young man from my religious group is like a trial for my brother & 0.530 \\
\hline Factor 5: Social radicalization & 1.6 \\
\hline Customs and social habits are a major cause of social progress & -0.657 \\
\hline Social justice is only for those who conform to social norms & -0.650 \\
\hline Sacred customs and traditions are to be followed & -0.607 \\
\hline Commitment to my relatives and tribe on all issues is a must even if it was not convincing to me & -0.516 \\
\hline The ideas of elders reflect the practices of sound social order & -0.545 \\
\hline Convincing others of my religious beliefs by force is right & -0.467 \\
\hline Failure to keep up with advanced countries is a result of the abandonment of social customs and values & -0.456 \\
\hline
\end{tabular}

Note. ${ }^{1}$ Extraction Method: Principal Component Analysis; Rotation Method: Quartimax with Kaiser Normalization.

\section{Geographical Differences}

The universities selected in this study were from three different geographical locations: In the north, Yarmouk University (the second largest university in Jordan), in the central part of Jordan, Jordan University (the largest university in Jordan), in the South, Tafila Technical University (a small size university) and Mutah University (a middle size university) (see Table 2). Findings showed geographical differences in radicalization with radicalization being least in the south and highest in the middle and the north. However, variations were also found within universities with Tafila University being highest on radicalization and Yarmouk University being the least on this dimension. Figure 2 shows these differences.

Table 2

Mean Radicalization by University

\begin{tabular}{llll}
\hline & $\mathrm{N}$ & Mean & SD \\
\hline Mutah (South) & 406 & 124.6626 & 31.92270 \\
Jordan (Center) & 202 & 132.7624 & 20.85327 \\
Yarmouk (North) & 194 & 132.5567 & 18.99112 \\
Tafilah (South) & 304 & 118.5461 & 33.97754 \\
Total & 1,106 & 125.8454 & 29.39367 \\
\hline
\end{tabular}

When testing for homogeneity of the variance using Leven's $\mathrm{F}$ test, significant difference were found $(F=$ $21.333, \alpha \leq 0.000)$. Table 3 shows significant differences in radicalization between universities $(F=14.049, \alpha$ $\leq 0.000)$. 


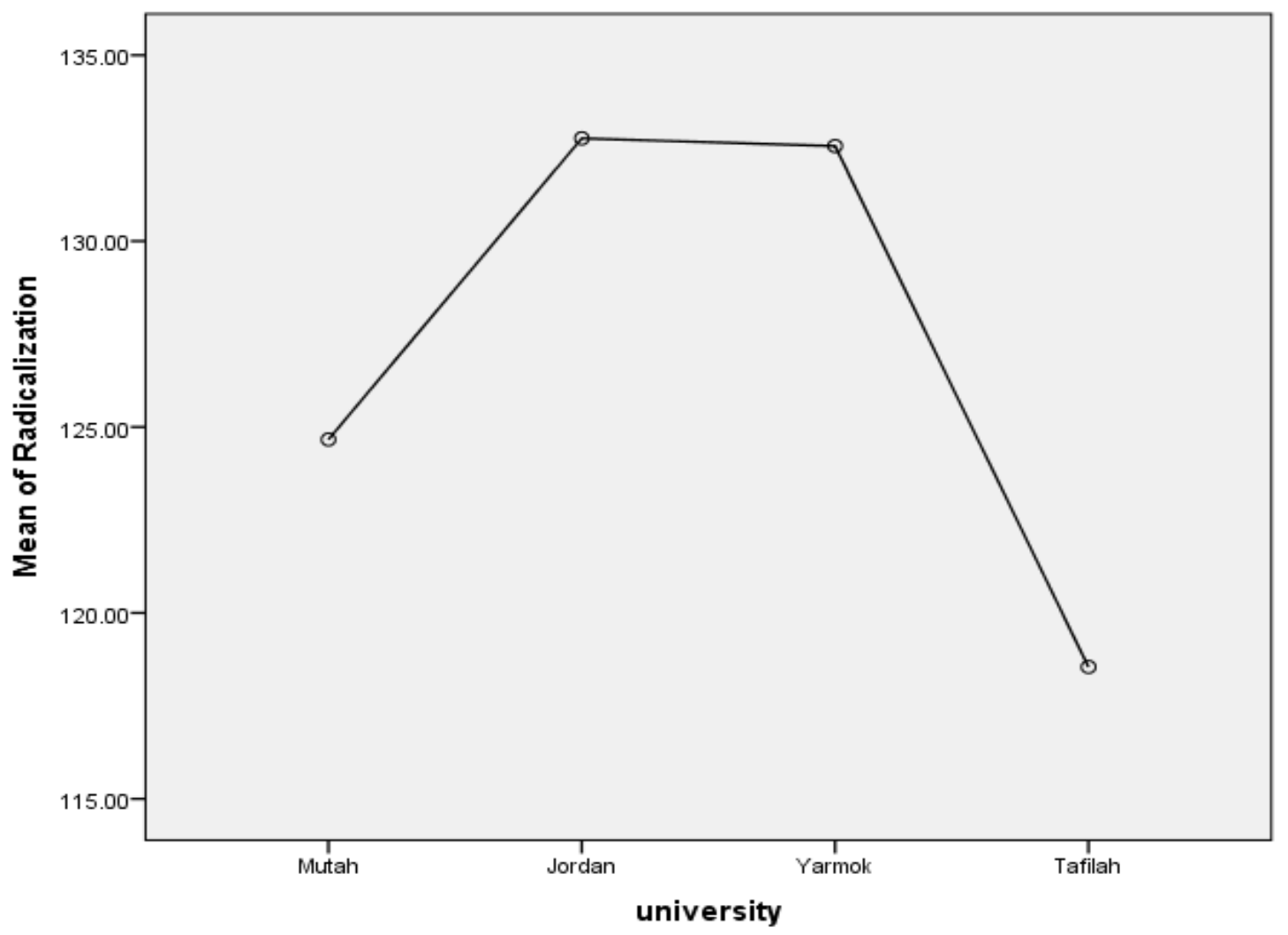

Figure 2. Universities differences in radicalization.

Table 3

ANOVA of University Differences in Radicalization

\begin{tabular}{lrrrrl}
\hline Sources & \multicolumn{1}{l}{ SS } & DF & MS & F & Sig \\
\hline Between Groups & $35,167.965$ & 3 & $11,722.655$ & 14.049 & 0.000 \\
Within Groups & $919,538.597$ & 1,102 & 834.427 & & \\
Total & $954,706.561$ & 1,105 & & & \\
\hline
\end{tabular}

\section{Gender Differences}

Findings showed non-significant differences between males and females in radicalization $(F=1.647, \alpha \leq$ 0.200). Table 4 shows the ANOVA analysis for the differences between males and females in radicalization (see Table 4). Descriptive results showed, however, that males have slightly higher mean on radicalism than females $(\mathrm{M}=127.2$ vs. 124$)$ with the same variation for both genders (29).

Table 4

\section{ANOVA Analysis for the Gender Differences in Radicalization}

\begin{tabular}{lccccl}
\hline Sources & \multicolumn{1}{l}{ SS } & DF & MS & F & Sig \\
\hline Between Groups & $1,424.552$ & 1 & $1,424.552$ & 1.647 & 0.200 \\
Within Groups & $952,982.748$ & 1,102 & 864.776 & & \\
Total & $954,407.301$ & 1,103 & & & \\
\hline
\end{tabular}

\section{College Differences}

Findings showed non-significant differences in radicalization between students of Arts and Humanities and students of Pure Sciences $(F=1.647, \alpha \leq 0.200)$. Table 5 shows the ANOVA analysis for the differences 
between these groups. Descriptive statistics show, however, that students of Arts and Humanities are more radicals than students of Science ( $M=127$ vs. 125$)$ with the same variation ( $M=29$ vs. 30$)$. Moreover, a significant difference was not found in the homogeneity of variance, assuming equal variance (Leven's $F=$ $0.479, \alpha \leq 0.489)$.

Table 5

ANOVA Analysis for Gender-mediated Differences in Radicalization

\begin{tabular}{lccccc}
\hline & Sum of Squares & df & Mean Square & F & Sig. \\
\hline Between Groups & $1,130.974$ & 1 & $1,130.974$ & 1.305 & 0.254 \\
Within Groups & $931,903.764$ & 1,075 & 866.887 & & \\
Total & $933,034.737$ & 1,076 & & & \\
\hline
\end{tabular}

\section{Discussion and Conclusion}

Findings revealed five factors representing five dimensions of college students' radicalization, namely political radicalization, religious radicalization, violent radicalization, group radicalization and social radicalization. All factors combined explained $45 \%$ of the variance of student radicalization. Regression analyses showed that radicalization among university students is a production of social and personal strains. In the first factor, the use or threat to use force was covered by extreme religious value, and viewed by university students as the only means for change. The second factor was colored by religious values which were based on religious ideology, excluding the others and enlarging the radicals" "I" and "we" when dealing with others. The third factor was covered by intolerance, hate and no sympathy with others. The forth factor was covered by group radicalization and being centered on group interest only. Finally the fifth factor was covered by social taboos and traditional rigid values that are colored by the tribal primacy.

On a global level, one can argue that the Middle-Eastern region and the country of Jordan specifically, are located in an unstable political and social area with wars and social movements happening all around, most notably after the events following the Arab Springs. These external strains combined with the public feeling of unjust and unfair rule in addition to the negative stigma of being a potential terrorist threat that got attached to the Arabs following the 9/11 terrorist attack. Two levels of injustice are felt among Jordanian youth; one on national level, where students encounter corruption, oppression of activists, unemployment and poverty and one on a global level, where they feel stigmatized as terrorists and looked down upon as savages and uncivilized. Social strains coupled with the aforementioned feelings create the right conditions that facilitate radicals' recruitment of young and vulnerable students on Jordan university campuses.

In this sense, radicalization might be interpreted in light of Agnew's General Stain Theory that states that terrorism is most likely when people experience 'collective strains' that are: (a) high in magnitude, with civilians affected; (b) unjust; and (c) inflicted by significantly more powerful others, including 'complicit' civilians, with whom members of the strained collectivity have weak ties. Radicalization might be thus explained in terms of strains similar to Agnew's (1992, 2001, 2002, \& 2010) theoretical explanation of terrorism. Drawing a parallel to Agnew's theory, collective strains increase the likelihood of radicalization, but they do not lead to terrorism in all cases. General strains produce negative feelings such as fear, anger and aggression and negative feelings can lead to criminal ideation.

In the Arab world, like everywhere else, college students are in a developmental stage that is typically characterized by psychological instability and crises (Al-badayneh, 2012). They are a sensitive and an unstable 
segment of society who face tremendous psychological and social strains. They are typically not well adjusted to society and, in a lot of ways, are not well integrated, disenfranchised and disillusioned with the role of the state. In this sense, they are very vulnerable and are predisposed to external influences including those of religious extremists who offer them political Islam as a viable alternative to available corrupt regimes. In fact, a reconnection with God and religion typically happens most when people experience psychological and social problems. Religious extremist know well how to capitalize on young students' vulnerabilities and take advantage of their social and political maladjustment and personal crises to radicalize them.

Radicals internalized the meanings of being radicals as Wiktorowicz (2004) described the production of meanings in his theory (a sub-branch of social movement theory) - called framing theory - that focuses on the social production and dissemination of meaning and on how individuals come to conceptualize themselves as a collectivity (Dalgaard-Nielsen, 2010, p. 801). Student radicalization is thus a zero-order belief about what students believe and how they develop and construct meanings for radical ideas transmitted to them through various social interactions including social significant others like their parents, teachers, colleagues and social networks. Radicalization seems to develop in incubators like the family, school and university within smaller groups, where bonding, peer pressure, and indoctrination gradually change the individual's view to a radical view (Sageman, 2004, p. 158; Wiktorowicz, 2004) as they share and transmit meanings.

As explained above, students are vulnerable to all forms of radicalization. They are a vulnerable and marginalized segment in society who feels excluded, disenfranchised, disgruntled, and alienated from the larger society. Religious radicals find the university environment as an ideal environment for recruitment for their political parties and even for terrorist activities. Thus universities become an incubator for radicals (Al-Badayneh, 2010). In the case of Jordanian universities students from the same kinship and tribes or region may often fail to integrate in a democratic educational system. What is seen is that the external mainstream social and tribal culture controls the university culture. The general public is conservative in nature, and students carry this culture into the university environment. With a sense of weak formal justice system students regress to their informal justice system (i.e., tribal justice system) and develop an informal network that protects them and make them secure. Universities can provide students with social skills through students NGOs and other forms of organizations that enhance other relationships (O'Koon, 1997). Students tend to withdraw into their own tribal, regional and ethnic group inside and outside the university. These types of interactions can facilitate and lead to different forms and levels of radicalization.

Moreover, findings showed no significant differences attributed to gender, and type of college. This means that students are equally prone to radicalization regardless of their gender and academic specialization. Differences in radicalization attributed to the university geographical location can be explained by the type of community surrounding the university. Universities located in heterogeneous social structures (Amman and Yarmouk) and environment was found to be higher in radicalization compared to universities located in the homogeneous communities (Tafila and Mutah). Similarities in radicalization attributed to gender and college type can be interpreted by the growing readiness of students to pursue and support far-reaching change in society that they conflict with, squeezed in or oppose a direct threat to the existing order that they saw as corrupted (Dalgaard-Nielsen, 2010).

Students who fight their fellow citizens and colleagues, and sometimes kill them for trivial social or tribal issues, do so because they believe that violent action is feasible and just. Within a tribal culture this can be seen as a restorative justice, due to the lack of open dialogue within the university environment, student may oddly resort 
to a maladaptive coping strategy such bullying, rage and fights to avoid severe social stigma. In this sense, radicalization is a process of internalizing a social set of beliefs and ideas with external negative forces of strains and negative emotions. The use of violence is thus seen as permissible and just. As Horgan stated "understanding involvement in terrorism and by association violent radicalization- requires a shift in focus from "the pursuit of profiles to the mapping of pathways" and from the search of "root causes to the identification of outer qualities" (Wilner \& Dubouloz, 2010).

A growing number of students experience a sense of unjust and a "wall of distrust", which means for some of them that they no longer take an interest in their environment and its rules and internalized stigma and lower expectation from the significant other in society (Harris, 1995). Feeling unjust treatments and insecurity can lead to the development of radical beliefs and acts (Reinares et al., 2008). From the early start, admission to Jordan University is based in most categories on unjust standards.

There is a knowledge gap with regards to the influence of public education including higher education (universities) on the onset or prevention of radicalization. To better understand the effect of university, policy as well as interventions can be developed to assist parents and teachers in preventing student radicalization (Pels \& de Ruyter, 2012). Law enforcement to maintain the university environment free of radicalization efforts is needed. Students training on human rights, diversity, and dialogue and tolerance should be included in university curricula.

It appears that marginalized groups among male and female youth, students at risk such as failures and poor students, and students who come from heterogeneous community are more vulnerable to radical recruitment than students are from homogeneous communities. A strategy to prevent radicalization among college students is therefore needed. As terrorism expert Brian Michael Jenkins rightly mentioned terrorists do not just happen, they are first radicalized and then they turn into terrorists (Gartenstein-Ross, Goodman, \& Grossman, 2009).

In discussing university students' radicalization, it is important to discuss a related opposite concept that of de-radicalization. The term de-radicalization and disengagement describe processes whereby individuals (or groups) cease their involvement in organized violence and/or terrorism. However, while de-radicalization aims for substantive changes in individuals' (or groups') ideology and attitudes, disengagement concentrates on the rejection of violent means (Ashour, 2009). University can educate and train its staff and students on collective and individual levels of de-radicalization and/or disengagement. Radicals can move to a more violent stage of thoughts and beliefs named extremism which used to refer to political ideologies that oppose a society's core values and principles. This could be applied to any ideology that advocates racial or religious supremacy and/or opposes the core principles of democracy and human rights (Scruton, 2007). Radical can be instigators who play a trigger role in collective radical violence.

To conclude, this study provides a valid and reliable scale that measures radicalization of university students that is consider an emerging global threat of sizeable magnitude. In most university campuses, this segment is very vulnerable to espousing radical ideology and thoughts lead to future terrorism. The scale can be easily applied to different societies and cultures. The use of this scale could make cross-cultural comparisons possible. Further empirical validations are however needed especially if the scale is to be used with a different segment of the population other than university students as these may have unique attributes not found in younger or older sub-groups. 


\section{References}

Agnew, R. (1992). Foundation for a general strain theory of crime and delinquency. Criminology, 30(1), 47-87.

Agnew, R. (2001). Building on the foundation of general strain theory: Specifying the types of strain most likely to lead to crime and delinquency. Journal of Research in crime and delinquency, 38(4), 319-361.

Agnew, R. (2002). Experienced, vicarious, and anticipated strain: An exploratory study focusing on physical victimization and delinquency. Justice Quarterly, 19(4), 603-32.

Agnew, R. (2010). General strain theory of terrorism. Theoretical Criminology, 14, 131-153.

Al-Badayneh, D. (2010). Human Development, Peace, Corruption, and Terrorism in the Arab World. International Journal of Security and Terrorism, 1(2), 63-85.

Al-Badayneh, D. (2012). Radicalization Incubators and Terrorism Recruitment in the Arab World. In Uses of the Internet in Financing and Recruitment Terrorism (pp. 1-44). NAUSS, KSA.

Ashour, O. (2009). The Deradicalization of Jihadists: Transforming Armed Islamist Movements. London, New York, Routledge.

Dalgaard-Nielsen, A. (2010). Violent radicalization in Europe: What we know and what we do not know. Studies in Conflict \& Terrorism, 33, 797-814.

Gartenstein-Ross, D., Goodman, J. D., \& Grossman, L. (2008). Terrorism in the West 2008: A Guide to Terrorism Events and Landmark Cases. Retrieved from http://www.humansecuritygateway.com/showRecord.php?RecordId=30297

Harris, J. R. (1995). Where is the child's environment? A group socialization theory of development. Psychological Review, $102(3), 458-489$.

Horgan, J. (2005a). The psychology of terrorism. Routledge.

Kaiser, H. F. (1974). An index of factorial simplicity. Psychometrika, 39, 31-36.

Mandel, D. R. (2010). Radicalization: What does it mean? In T. M. Pick, A. Speckhard, \& B. Jacuch (Eds.), Home-grown terrorism: Understanding and addressing the root causes of radicalization among groups with an immigrant heritage in Europe (pp. 101-113). Amsterdam, Netherlands: IOS Press.

McCauley, C., \& Moskalenko, S. (2008). Mechanisms of political radicalization: Pathways toward terrorism. Retrieved from http://www.tandfonline.com/doi/abs/10.1080/09546550802073367

O'Koon, J. (1997). Attachment to parents and peers in late adolescence and their relationship with self-image. Journal of Adolescence, 32(4), 470-482.

Parent, R., \& Ellis, J. (2011). Countering Radicalization of Diaspora communities in Canada. Retrieved from http://mbc.metropolis.net/assets/uploads/files/wp/2011/WP11-12.pdf

Pels, T. \& de Ruyter, D. (2012). The influences of education and socialization on radicalization: An exploration of theoretical presumptions and empirical research. Child Youth Care Forum, 41, 311-325.

Precht, T. (2007). Home grown terrorism and Islamist radicalization in Europe From conversion to terrorism An assessment of the factors influencing violent Islamist extremism and suggestions for counter radicalization measures. Retrieved from Home_grown_terrorism_and_Islamist_radicalisation_in_Europe_-_an_assessment_of_influencing_factors.pdf

Pressman, E. (2008). Exploring the sources of radicalization and violent radicalization: Transatlantic perspectives. Journal of Security Issues, 2, 1-20.

Reinares, F., Alonso, R., Bjo“rgo, T., Della Porta, D., Coolsaet, R., Khosrokhavar, F., \& De Vries, G. (2008). Radicalization processes leading to acts of terrorism: A concise report prepared by the European Commission's expert group on violent radicalization. N.p.

Richard, A. (2011). The problem with radicalization: The remit of "prevent" and the need to refocus on terrorism in the UK. International Affaires, 87(1), 143-152.

Royal Canadian Mounted Police (RCMP). (2007). Radicalization to Violence: Definition of Radicalization. Retrieved from http://www.rcmp-grc.gc.ca/nsci-ecsn/rad/internet/p2-eng.htm

Sageman, M. (2004). Understanding Terror Networks. Philadelphia: University of Pennsylvania Press.

Sageman, M. (2007). Modern bioterrorism. Department of Homeland Security, Science and Technology Directorate, Washington, D.C.

Scruton, R. (2007). The Palgrave Macmillan dictionary of political thought (3rd ed.). Basingstoke: Palgrave Macmillan.

Silke, E. (2008). Holy Warriors: Exploring the psychological processes of Jihadi Radicalization. European Journal of Criminology, 5(1), 99-123. 
Webber, D. (2011). Education as counterterrorism tool and the curious case of the Texas school book resolution. Retrieved from http://works.bepress.com/diane_webber/10

Weinberg, L., Pedahzur, A., \& Hirsch-Hoefler, S. (2004). The Challenges of Conceptualizing Terrorism. Retrieved from http://www.tandfonline.com/doi/abs/10.1080/095465590899768

Wiktorowicz, Q. (2004). Introduction: Islamic activism and social movement theory. In Q. Wiktorowicz (Ed.), Islamic activism: A social movement theory approach. Bloomington, IN: Indiana University Press.

Wilner, A., \& Dubouloz, C. (2011). Transformative radicalization: Applying learning theory to Islamist radicalization. Studies in Conflict \& Terrorism, 34, 418-438. 